Virginia Commonwealth University VCU Scholars Compass

\title{
Eltrombopag for Thrombocytopenia in Patients with Cirrhosis Associated with Hepatitis C
}

John G. McHutchison

Duke University

Geoffrey Dusheiko

Royal Free Hospital

Mitchell L. Shiffman

Virginia Commonwealth University

See next page for additional authors

Follow this and additional works at: http://scholarscompass.vcu.edu/vcuhealth_pubs

Part of the Medicine and Health Sciences Commons

From The New England Journal of Medicine, McHutchison, J. G., Dusheiko, G., Shiffman, M. L. et al., Eltrombopag for Thrombocytopenia in Patients with Cirrhosis Associated with Hepatitis C, Vol. 357, Page 2227, Copyright (C) 2007 Massachusetts Medical Society. Reprinted with permission.

\section{Downloaded from}

http://scholarscompass.vcu.edu/vcuhealth_pubs/16

This Article is brought to you for free and open access by the VCU Health at VCU Scholars Compass. It has been accepted for inclusion in VCU Health Publications by an authorized administrator of VCU Scholars Compass. For more information, please contact libcompass@vcu.edu. 


\section{Authors}

John G. McHutchison, Geoffrey Dusheiko, Mitchell L. Shiffman, Maribel Rodriguez-Torres, Samuel Sigal, Marc Bourliere, Thomas Berg, Stuart C. Gordon, Fiona M. Campbell, Dickens Theodore, Nicole Blackman, Julian Jenkins, and Nezam H. Afdhal 


\title{
The NEW ENGLAN D \\ JOURNAL of MEDICINE
}

\section{Eltrombopag for Thrombocytopenia in Patients with Cirrhosis Associated with Hepatitis C}

\author{
John G. McHutchison, M.D., Geoffrey Dusheiko, M.D., Mitchell L. Shiffman, M.D., Maribel Rodriguez-Torres, M.D., \\ Samuel Sigal, M.D., Marc Bourliere, M.D., Thomas Berg, M.D., Stuart C. Gordon, M.D., Fiona M. Campbell, B.Sc., \\ Dickens Theodore, M.D., M.P.H., Nicole Blackman, Ph.D., Julian Jenkins, M.Sc., and Nezam H. Afdhal, M.D., \\ for the TPL102357 Study Group*
}

ABSTRACT

\section{BACKGROUND}

Eltrombopag is a new, orally active thrombopoietin-receptor agonist that stimulates thrombopoiesis. We evaluated its ability to increase platelet counts and facilitate treatment for hepatitis $\mathrm{C}$ virus (HCV) infection in patients with thrombocytopenia associated with HCV-related cirrhosis.

\section{METHODS}

Seventy-four patients with HCV-related cirrhosis and platelet counts of 20,000 to less than 70,000 per cubic millimeter were randomly assigned to receive eltrombopag (30, 50, or $75 \mathrm{mg}$ daily) or placebo daily for 4 weeks. The primary end point was a platelet count of 100,000 per cubic millimeter or more at week 4. Peginterferon and ribavirin could then be initiated, with continuation of eltrombopag or placebo for 12 additional weeks.

\section{RESULTS}

At week 4, platelet counts were increased to 100,000 per cubic millimeter or more in a dose-dependent manner among patients for whom these data were available: in 0 of the 17 patients receiving placebo, in 9 of 12 (75\%) receiving $30 \mathrm{mg}$ of eltrombopag, in 15 of 19 (79\%) receiving $50 \mathrm{mg}$ of eltrombopag, and in 20 of 21 (95\%) receiving $75 \mathrm{mg}$ of eltrombopag $(\mathrm{P}<0.001)$. Antiviral therapy was initiated in 49 patients (in 4 of 18 patients receiving placebo, 10 of 14 receiving $30 \mathrm{mg}$ of eltrombopag, 14 of 19 receiving $50 \mathrm{mg}$ of eltrombopag, and 21 of 23 receiving $75 \mathrm{mg}$ of eltrombopag) while the administration of eltrombopag or placebo was continued. Twelve weeks of antiviral therapy, with concurrent receipt of eltrombopag or placebo, were completed by $36 \%, 53 \%$, and $65 \%$ of patients receiving $30 \mathrm{mg}, 50 \mathrm{mg}$, and $75 \mathrm{mg}$ of eltrombopag, respectively, and by $6 \%$ of patients in the placebo group. The most common adverse event during the initial 4 weeks was headache; thereafter, the adverse events were those expected with interferon-based therapy.

\section{CONCLUSIONS}

Eltrombopag therapy increases platelet counts in patients with thrombocytopenia due to HCV-related cirrhosis, thereby permitting the initiation of antiviral therapy. (ClinicalTrials.gov number, NCT00110799.)
From Duke University and Duke Clinical Research Institute, Durham, NC (J.G.M.); Royal Free Hospital, London (G.D.); Virginia Commonwealth University Medical Center, Richmond (M.L.S.); Fundación de Investigación de Diego, San Juan, Puerto Rico (M.R.-T.); Weill Medical College of Cornell University, New York (S.S.); Hôpital Saint Joseph, Marseille, France (M.B.); Charité, Berlin (T.B.); Henry Ford Hospital and Health System, Detroit (S.C.G.); GlaxoSmithKline, Greenford, United Kingdom (F.M.C.); GlaxoSmithKline, Research Triangle Park, NC (D.T.); GlaxoSmithKline, Philadelphia (N.B.,J.J.); and Beth Israel Deaconess Medical Center, Boston (N.H.A.). Address reprint requests to $\mathrm{Dr}$. McHutchison at Duke University and Duke Clinical Research Institute, P.O. Box 17969, Durham, NC27705, or at mchut001@mc.duke.edu.

*The members of the TPL102357 Study Group are listed in the Appendix.

N Engl J Med 2007;357:2227-36.

Copyright (c) 2007 Massachusetts Medical Society. 
T HROMBOCYTOPENIA IS A FREQUENT complication of chronic liver disease and is considered an indicator of advanced disease. ${ }^{1-3}$ The low platelet count is due partly to the effects of portal hypertension and hypersplenism, ${ }^{4}$ decreased thrombopoietin production, ${ }^{2,5,6}$ and virus-induced bone marrow suppression..$^{7,8}$

Patients with chronic liver disease due to infection with the hepatitis $\mathrm{C}$ virus ( $\mathrm{HCV}$ ) who have thrombocytopenia $(<75,000$ platelets per cubic millimeter) have been routinely excluded from clinical trials of interferon and ribavirin, and few published reports have described the treatment of chronic HCV infection in patients with platelet counts of less than 50,000 per cubic millimeter. Although a reduced platelet count is not an absolute contraindication to treatment with pegylated interferon (peginterferon) and ribavirin, product labels advise that caution be used in treating patients with clinically significant thrombocytopenia. Furthermore, if thrombocytopenia develops during antiviral therapy, peginterferon may need to be delivered at a reduced dose or discontinued.9,10 Currently, there is no approved treatment for thrombocytopenia in patients with HCV infection.

Eltrombopag (SB-497115, GlaxoSmithKline) is a new, small-molecule, nonpeptide, oral platelet growth factor that acts as a thrombopoietin-receptor agonist. The drug interacts with the transmembrane domain of the thrombopoietin receptor and induces proliferation and differentiation of megakaryocytes and, as a result, an increase in platelet production. In preclinical and early clinical studies, eltrombopag therapy was shown to stimulate megakaryocyte proliferation and differentiation and to cause dose-dependent increases in platelet counts in chimpanzees and humans. ${ }^{11-14}$ Ex vivo experiments with platelets from humans and in vivo studies of healthy subjects have shown that treatment with eltrombopag does not adversely affect platelet function. ${ }^{15,16}$ Eltrombopag has also been shown to increase platelet counts in a dose-dependent manner in patients with chronic immune thrombocytopenic purpura. ${ }^{17}$

In this phase 2 study, we assessed whether the use of eltrombopag can increase platelet counts in patients with thrombocytopenia associated with cirrhosis due to chronic HCV infection. The safety and adverse-event profiles of eltrombopag were also evaluated.

\section{METHODS}

\section{PATIENTS}

Patients were enrolled from 22 centers in the United States and Europe. Eligible patients were 18 years of age or older and had chronic HCV infection (defined as the presence of anti-HCV antibodies and detectable serum HCV RNA levels, as determined with the use of a clinically available assay chosen by the investigator), compensated liver disease, and thrombocytopenia (defined as a platelet count of 20,000 to $<70,000$ per cubic millimeter). Patients were also required to have a liver-biopsy specimen indicative of cirrhosis, radiographic evidence of cirrhosis, or endoscopic evidence of portal hypertension. Patients were excluded if they were pregnant, had a history of thrombosis, or were coinfected with the human immunodeficiency virus or the hepatitis B virus.

Our study was approved by the institutional review board or ethics committee at each participating center and was conducted in accordance with the provisions of the Declaration of Helsinki, Good Clinical Practice guidelines, and local laws and regulations. All patients provided written informed consent.

\section{STUDY DESIGN AND ORGANIZATION}

Our study was an international, multicenter, double-blind, randomized, placebo-controlled, phase 2 trial covering a range of doses of eltrombopag. After meeting the eligibility criteria, patients were randomly assigned to study groups in a 1:1:1:1 ratio with the use of permuted-block randomization and a block size of four. The random assignment was stratified according to the baseline platelet count $(20,000$ to $<50,000$ per cubic millimeter vs. 50,000 to $<70,000$ per cubic millimeter). $\mathrm{Pa}$ tients were assigned to an eltrombopag group or the placebo group by means of central randomization, which was independent of the study centers and involved an interactive voice system. In the initial treatment phase, patients received either eltrombopag tablets, once daily, at a dose of $30 \mathrm{mg}$, $50 \mathrm{mg}$, or $75 \mathrm{mg}$ or matching placebo, once daily, for 4 weeks (Fig. 1). Hematologic, biochemical, and other safety assessments were performed weekly. Treatment with eltrombopag was interrupted if the platelet count was 200,000 or more per cubic millimeter; treatment was then reinstat- 


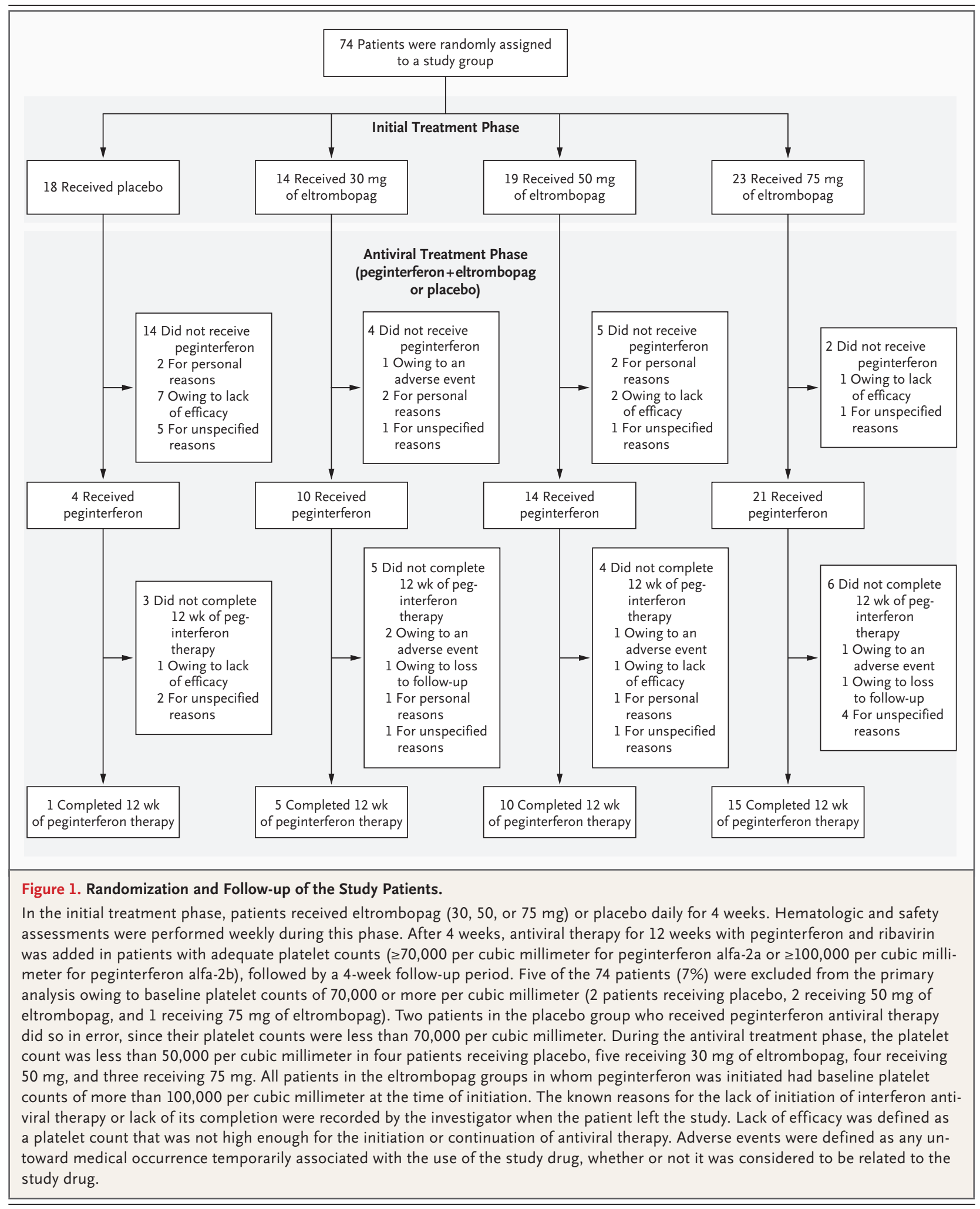


ed on an individual basis, generally when platelet counts returned to 100,000 or less per cubic millimeter.

Patients who completed the initial treatment phase were eligible for antiviral treatment if they had attained a predefined platelet count: 70,000 or more per cubic millimeter for the use of peginterferon alfa-2a (Pegasys, Roche) or 100,000 or more per cubic millimeter for the use of peginterferon alfa-2b (Peg-Intron, Schering-Plough). The choice of interferon was not dictated by the protocol but rather was at the investigator's discretion.

In this antiviral treatment phase, peginterferon (180 $\mu \mathrm{g}$ of peginterferon alfa-2a per week or 1.5 $\mu \mathrm{g}$ of peginterferon alfa-2b per kilogram of body weight per week) and ribavirin (1000 to $1200 \mathrm{mg}$ per day for patients receiving peginterferon alfa$2 \mathrm{a}$ and $800 \mathrm{mg}$ per day for those receiving peginterferon alfa-2b) were administered for 8 weeks concomitantly with eltrombopag or placebo. Once additional preclinical safety data were available, the protocol was amended to extend this phase to 12 weeks, at which time eltrombopag was stopped and antiviral therapy was continued at the investigator's discretion. A follow-up visit was scheduled for 4 weeks after the last dose of eltrombopag or placebo had been received. Throughout the antiviral treatment phase, in accordance with the product labels for these approved therapies, the dose of peginterferon alfa-2a was reduced by half if the platelet count had decreased to 25,000 to 50,000 per cubic millimeter and was discontinued altogether if the platelet count was below 25,000 per cubic millimeter. The dose of peginterferon alfa-2b was reduced by half if the platelet count had decreased to 50,000 to 80,000 per cubic millimeter and was discontinued altogether if the platelet count was less than 50,000 per cubic millimeter.

An independent data monitoring committee was established to review data during the study. A separate independent committee reviewed all ophthalmic evaluations, because ocular findings in preclinical studies of immature rodents indicated a risk of cataract formation.

The sponsor, GlaxoSmithKline, and the academic principal investigator designed the study, developed the protocol, and prepared the first and subsequent drafts of the manuscript, with input from participating academic investigators. The sponsor and the academic principal investigator held and analyzed the data. Decisions related to the content of the final draft of the manuscript were made by the academic principal investigator in consultation with all coauthors. All authors, four of whom are employees of GlaxoSmithKline, had access to the data and contributed to the writing of the manuscript. The academic principal investigator vouches for the completeness and accuracy of this article.

\section{STATISTICAL ANALYSIS}

The primary efficacy end point was an increase in the platelet count from the baseline value $(20,000$ to $<70,000$ per cubic millimeter) to 100,000 or more per cubic millimeter after the 4-week initial treatment phase. Secondary end points included those related to safety, tolerability, and the ability to continue peginterferon therapy during the antiviral treatment phase. The analyses included all patients who were randomly assigned to a study group and who received at least one dose of the study medication. In the analysis of the primary end point, however, data for 5 of the 74 patients (7\%) who entered the study but whose baseline platelet count was 70,000 or more per cubic millimeter were excluded; missing data were imputed with the use of the last-observation-carried-forward approach.

We planned to enroll 160 patients in the study, with 40 patients randomly assigned to each study group. We estimated the number of patients assuming a rate of response of $20 \%$ in the placebo group and $60 \%$ in the three active treatment groups. The power of our study to detect this anticipated treatment effect was $90 \%$ at an overall two-sided level of significance of $5 \%$. The primary end point was analyzed with the use of multiple logistic-regression analysis. Each of the three eltrombopag groups was compared with the placebo group by means of a closed testing procedure. We tested the global null hypothesis of no significant difference among the four study groups and, if this global hypothesis was rejected, the null hypothesis of no significant difference between the placebo group and each eltrombopag group, with testing performed in the predetermined order of the highest dose (75 $\mathrm{mg}$ ) to the lowest dose $(30 \mathrm{mg})$. The sequential testing was continued until the null hypothesis could not be rejected.

The study was originally planned to be performed without interim analyses, except for a blinded review by the independent data monitor- 
ing committee of the safety and adverse-event profiles after 40 patients had completed the initial treatment phase. A subsequent amendment to the protocol stipulated the performance of formal interim analyses of efficacy data from the initial treatment phase.

The criterion for stopping the study early was a two-sided $\mathrm{P}$ value no greater than 0.0001 , based on the O'Brien-Fleming adjustment for a groupsequential design, from an interim analysis of the efficacy data. ${ }^{18}$ The criterion was not met in the first interim analysis but was met in the second interim analysis (overall comparison for the four study groups, $\mathrm{P}<0.0001 ; 30 \mathrm{mg}$ of eltrombopag vs. placebo, $\mathrm{P}=0.00067 ; 50 \mathrm{mg}$ of eltrombopag vs. placebo, $\mathrm{P}=0.00015$; and $75 \mathrm{mg}$ of eltrombopag vs. placebo, $\mathrm{P}<0.0001)$.

\section{RES ULTS}

\section{CHARACTERISTICS OF THE PATIENTS}

Between April 5, 2005, and October 20, 2006, a total of 74 patients were randomly assigned to a study group and received the study drug or placebo (Fig. 1): 18 patients received placebo, 14 received $30 \mathrm{mg}$ of eltrombopag, 19 received $50 \mathrm{mg}$ of eltrombopag, and 23 received $75 \mathrm{mg}$ of eltrombopag. Since the 74 patients were distributed across 22 sites, some sites did not use a complete block, which caused a slight imbalance in the numbers of patients assigned to the four groups. The demographic and baseline clinical characteristics of the study groups were well balanced (Table 1). The median age was 51 years (range, 30 to 74 ), and more than two thirds of the patients were men.

\begin{tabular}{|c|c|c|c|c|c|}
\hline Characteristic & & Eltrombopag & & Placebo $(\mathrm{N}=18$ ) & All $(\mathrm{N}=74)$ \\
\hline \multicolumn{6}{|l|}{ Age $-y r$} \\
\hline Median & 56 & 50 & 51 & 52 & 51 \\
\hline Range & $43-74$ & $30-72$ & $38-60$ & $41-71$ & $30-74$ \\
\hline \multicolumn{6}{|l|}{ Sex - no. (\%) } \\
\hline Male & $10(71)$ & $12(63)$ & $19(83)$ & $11(61)$ & $52(70)$ \\
\hline Female & $4(29)$ & $7(37)$ & $4(17)$ & 7 (39) & $22(30)$ \\
\hline \multicolumn{6}{|l|}{ Race - no. (\%) † } \\
\hline Black & 0 & $2(11)$ & $1(4)$ & $1(6)$ & $4(5)$ \\
\hline Asian & 0 & $1(5)$ & 0 & $1(6)$ & $2(3)$ \\
\hline White & $13(93)$ & $16(84)$ & $22(96)$ & $16(89)$ & $67(91)$ \\
\hline \multicolumn{6}{|l|}{ Platelet count } \\
\hline Median - per $\mathrm{mm}^{3}$ & 59,000 & 52,000 & 54,000 & 55,000 & 55,000 \\
\hline Range - per $\mathrm{mm}^{3}$ & $34,000-94,000$ & $26,000-66,000$ & $28,000-75,000$ & $27,000-75,000$ & $26,000-94,000$ \\
\hline 20,000 to $<50,000 / \mathrm{mm}^{3}-$ no. (\%) & $5(36)$ & $7(37)$ & $8(35)$ & $6(33)$ & $26(35)$ \\
\hline$\geq 50,000$ to $<70,000 / \mathrm{mm}^{3}-$ no. (\%) & $7(50)$ & $12(63)$ & $13(57)$ & $11(61)$ & $43(58)$ \\
\hline$\geq 70,000 / \mathrm{mm}^{3}-$ no. (\%) & $2(14)$ & 0 & $2(9)$ & $1(6)$ & $5(7)$ \\
\hline \multicolumn{6}{|l|}{ HCV genotype - no. (\%) } \\
\hline 1 or 4 & $10(71)$ & $11(58)$ & $14(61)$ & $10(56)$ & $45(61)$ \\
\hline 2 or 3 & $4(29)$ & $8(42)$ & $8(35)$ & $7(39)$ & $27(36)$ \\
\hline Unknown & 0 & 0 & $1(4)$ & $1(6)$ & $2(3)$ \\
\hline Albumin - g/liter & $35.8 \pm 6.8$ & $33.8 \pm 4.9$ & $36.6 \pm 5.7$ & $36.4 \pm 5.8$ & $35.7 \pm 5.7$ \\
\hline Alanine aminotransferase - IU/liter & $120.6 \pm 51.4$ & $117.8 \pm 67.5$ & $117.0 \pm 69.3$ & $120.5 \pm 70.7$ & $118.8 \pm 64.2$ \\
\hline Aspartate aminotransferase - IU/liter & $123.3 \pm 68.1$ & $127.4 \pm 67.3$ & $128.6 \pm 104.1$ & $129.5 \pm 72.8$ & $127.5 \pm 79.2$ \\
\hline Total bilirubin $-\mu \mathrm{mol} /$ liter & $25.3 \pm 11.5$ & $25.1 \pm 14.1$ & $24.9 \pm 16.3$ & $27.7 \pm 14.0$ & $25.7 \pm 14.4$ \\
\hline
\end{tabular}

* Plus-minus values are means \pm SD. There were no significant differences in characteristics between the study groups. HCV denotes hepatitis $C$ virus. To convert values for total bilirubin to milligrams per deciliter, divide by 17.1.

$\uparrow$ Race was self-reported; data were not available for one patient. 
The median baseline platelet count was 55,000 per cubic millimeter (range, 26,000 to 94,000). The baseline platelet count was 20,000 to less than 50,000 per cubic millimeter in $35 \%$ of patients (26 of 74) and 50,000 to less than 70,000 per cubic millimeter in $58 \%$ (43 of 74) (Table 1 ). Seven percent of patients ( 5 of 74 ) who were successfully screened had baseline platelet counts of 70,000 or more per cubic millimeter just before administration of the study drug, which was considered a violation of the protocol. Therefore, the data for these five patients were excluded from the analysis of the primary efficacy end point, but they were included in the safety analysis because the patients received the study drug.

\section{EFFICACY}

Initial Treatment Phase

The receipt of eltrombopag increased platelet counts to 100,000 or more per cubic millimeter at week 4 , in a dose-dependent manner $(\mathrm{P}<0.001$ for overall treatment effect) (Table 2). The effect of each dose of eltrombopag was significant $(\mathrm{P}<0.001)$, as compared with the effect of placebo. No patient in the placebo group had an increase in the platelet count to 100,000 or more per cubic millimeter after 4 weeks. The results for the primary end point based on the observed data only (i.e., those obtained without the application of the last-observation-carried-forward approach) were similar to the results when the last-observation-carried-for-

\begin{tabular}{|c|c|c|c|c|}
\hline \multirow[t]{2}{*}{ Variable } & \multicolumn{3}{|c|}{ Eltrombopag } & \multirow[t]{2}{*}{ Placebo $(\mathrm{N}=18)$} \\
\hline & $30 \mathrm{mg}(\mathrm{N}=14)$ & $50 \mathrm{mg}(\mathrm{N}=19)$ & $75 \mathrm{mg}(\mathrm{N}=23)$ & \\
\hline \multicolumn{5}{|l|}{ End of initial treatment phase } \\
\hline \multicolumn{5}{|l|}{ Platelet count } \\
\hline No. of patients with data & 11 & 16 & 22 & 14 \\
\hline Median - per $\mathrm{mm}^{3}$ & 125,000 & 212,000 & 204,000 & 53,000 \\
\hline Range - per $\mathrm{mm}^{3}$ & 40,000 to 214,000 & 47,000 to 599,000 & 78,000 to 527,000 & 34,000 to 74,000 \\
\hline \multicolumn{5}{|l|}{ Change from baseline } \\
\hline No. of patients with data & 12 & 16 & 22 & 14 \\
\hline Median - per $\mathrm{mm}^{3}$ & 74,000 & 152,000 & 151,000 & $-3,000$ \\
\hline Range - per $\mathrm{mm}^{3}$ & 6,000 to 155,000 & 10,000 to 540,000 & 45,000 to 473,000 & $-22,000$ to 13,000 \\
\hline $\begin{array}{l}\geq 100,000 / \mathrm{mm}^{3}-\text { no. of responders/total no. } \\
\text { of patients who could be evaluated (\%) }\end{array}$ & $9 / 12(75)$ & $15 / 19(79)$ & $20 / 21(95)$ & $0 / 17$ \\
\hline $\begin{array}{l}\geq 200,000 / \mathrm{mm}^{3}-\text { no. of responders/total no. } \\
\text { of patients who could be evaluated (\%) }\end{array}$ & $3 / 12(25)$ & $9 / 19(47)$ & $11 / 21(52)$ & $0 / 17$ \\
\hline \multicolumn{5}{|l|}{ End of antiviral treatment phase } \\
\hline \multicolumn{5}{|l|}{ Platelet count } \\
\hline No. of patients with data & 2 & 7 & 8 & 1 \\
\hline Median - per $\mathrm{mm}^{3}$ & 106,000 & 100,000 & 92,000 & 39,000 \\
\hline Range - per $\mathrm{mm}^{3}$ & 43,000 to 164,000 & 46,000 to 156,000 & 38,000 to 245,000 & 39,000 to 39,000 \\
\hline \multicolumn{5}{|l|}{ Change from baseline - per $\mathrm{mm}^{3}$} \\
\hline Median & 31,000 & 54,000 & 31,000 & $-25,000$ \\
\hline Range & $-18,000$ to 122,000 & 8000 to 97,000 & $-23,000$ to 191,000 & $-25,000$ to $-25,000$ \\
\hline
\end{tabular}

* Data were not available for some patients because of withdrawal from the study before week 4 or for other reasons. Patients who could be evaluated were those whose data were included in the last-observation-carried-forward analysis in the intention-to-treat population and excluded those with a platelet count of less than 20,000 per cubic millimeter or 70,000 or more per cubic milliliter at baseline or those for whom the platelet count was unknown during the antiviral treatment phase. The overall $P$ value for the treatment effect at the end of the initial treatment phase was less than 0.001 , as were the $P$ values for the comparison of each eltrombopag group with the placebo group with respect to the percentages of patients with platelet counts of 100,000 or more per cubic millimeter at the end of the initial treatment phase. 
ward approach was used. Between 25 and 52\% of patients receiving eltrombopag (primarily those receiving 50-mg or 75-mg doses daily) had platelet counts of 200,000 or more per cubic millimeter at any time during the initial treatment phase. Treatment with eltrombopag was interrupted in these patients until their platelet counts decreased to 100,000 or fewer per cubic millimeter.

\section{Antiviral Treatment Phase}

Overall, two thirds of the patients (49 of 74) proceeded to the antiviral treatment phase: 4 of the 18 patients (22\%) receiving placebo and 10 of the 14 (71\%), 14 of the 19 (74\%), and 21 of the $23(91 \%)$ receiving $30 \mathrm{mg}, 50 \mathrm{mg}$, and $75 \mathrm{mg}$ of eltrombopag, respectively (Fig. 1). Of these 49 patients, 48 had a platelet count that met the prespecified threshold for entry into the antiviral treatment phase $(\geq 70,000$ per cubic millimeter for the use of peginterferon alfa-2a or $\geq 100,000$ per cubic millimeter for the use of peginterferon alfa-2b), and therefore peginterferon-based therapy could be initiated (Fig. 1).

On an intention-to-treat basis, the first 12 weeks of antiviral therapy were completed by 5 of 14 patients receiving $30 \mathrm{mg}$ of eltrombopag (36\%), 10 of 19 receiving $50 \mathrm{mg}(53 \%)$, and 15 of 23 receiving $75 \mathrm{mg}(65 \%)$, as compared with 1 of 18 patients (6\%) in the placebo group (Fig. 2). Platelet counts in all eltrombopag groups decreased during the antiviral treatment phase, despite continued treatment with eltrombopag, but remained consistently above baseline values, with a nadir of more than 50,000 per cubic millimeter (Table 2 and Fig. 2). Among the patients who completed the 12-week antiviral treatment phase and for whom platelet counts were available, a platelet count greater than the baseline value was maintained after completion of the antiviral treatment phase in 0 of 1 patient receiving placebo, 4 of 5 receiving $30 \mathrm{mg}$ of eltrombopag, 4 of 5 receiving $50 \mathrm{mg}$ of eltrombopag, and 10 of 12 receiving $75 \mathrm{mg}$ of eltrombopag.

At all time points during the antiviral treatment phase, platelet counts in all three eltrombopag groups were higher than those in the placebo group and remained higher than the level at which a reduction in the peginterferon dose is recommended ( $<50,000$ per cubic millimeter). In the group receiving $75 \mathrm{mg}$ of eltrombopag, 18 of 21 patients had platelet counts of 50,000 or more per cubic millimeter during this phase. No patient in the placebo group had a platelet count this high while receiving antiviral therapy. In the initial or antiviral treatment phase, platelet counts exceeded the protocol-specified upper limit of 200,000 per cubic millimeter in at least one visit in 4 of 14 patients (29\%), 9 of 19 (47\%), and 16 of $23(70 \%)$ in the groups receiving $30 \mathrm{mg}$ of eltrombopag, $50 \mathrm{mg}$ of eltrombopag, and $75 \mathrm{mg}$ of eltrombopag, respectively, necessitating a temporary interruption in eltrombopag therapy.

\section{SAFETY}

During the 4-week initial treatment phase, headache was reported in $36 \%, 16 \%$, and $17 \%$ of patients who received $30 \mathrm{mg}$ of eltrombopag, $50 \mathrm{mg}$ of eltrombopag, and $75 \mathrm{mg}$ of eltrombopag, respectively, as well as in $17 \%$ of patients who received placebo (Table 3). Other common adverse events in the three eltrombopag groups were dry mouth, abdominal pain, and nausea.

During the subsequent antiviral treatment phase, the incidence of adverse events was similar in all three eltrombopag groups. The adverse events most commonly reported during this phase were influenza-like illness, fatigue, chills, and headache, all of which are known side effects of interferon-based therapy. ${ }^{19,20}$

Drug-related adverse events were reported for five patients receiving $30 \mathrm{mg}$ of eltrombopag (36\%), eight receiving $50 \mathrm{mg}(42 \%)$, and eight receiving $75 \mathrm{mg}$ (35\%), as compared with three patients $(17 \%)$ in the placebo group. The most frequent drug-related adverse events (all of low-grade severity) were dry mouth, headache, and nausea. After treatment had been discontinued, thrombocytopenia occurred in one patient receiving $30 \mathrm{mg}$ of eltrombopag, decreased visual acuity occurred in another receiving $30 \mathrm{mg}$ of eltrombopag, and petechiae occurred in one patient receiving $75 \mathrm{mg}$ of eltrombopag.

During the entire study, 62 patients reported adverse events and 7 reported serious adverse events. These serious events included ascites (in the group receiving $30 \mathrm{mg}$ of eltrombopag), which subsequently resolved, and retinal exudates (in the group receiving $75 \mathrm{mg}$ of eltrombopag), which did not resolve and which were deemed by the investigator to be unrelated to treatment with eltrombopag. Thrombocytopenia in one patient receiving $30 \mathrm{mg}$ of eltrombopag and myositis in 


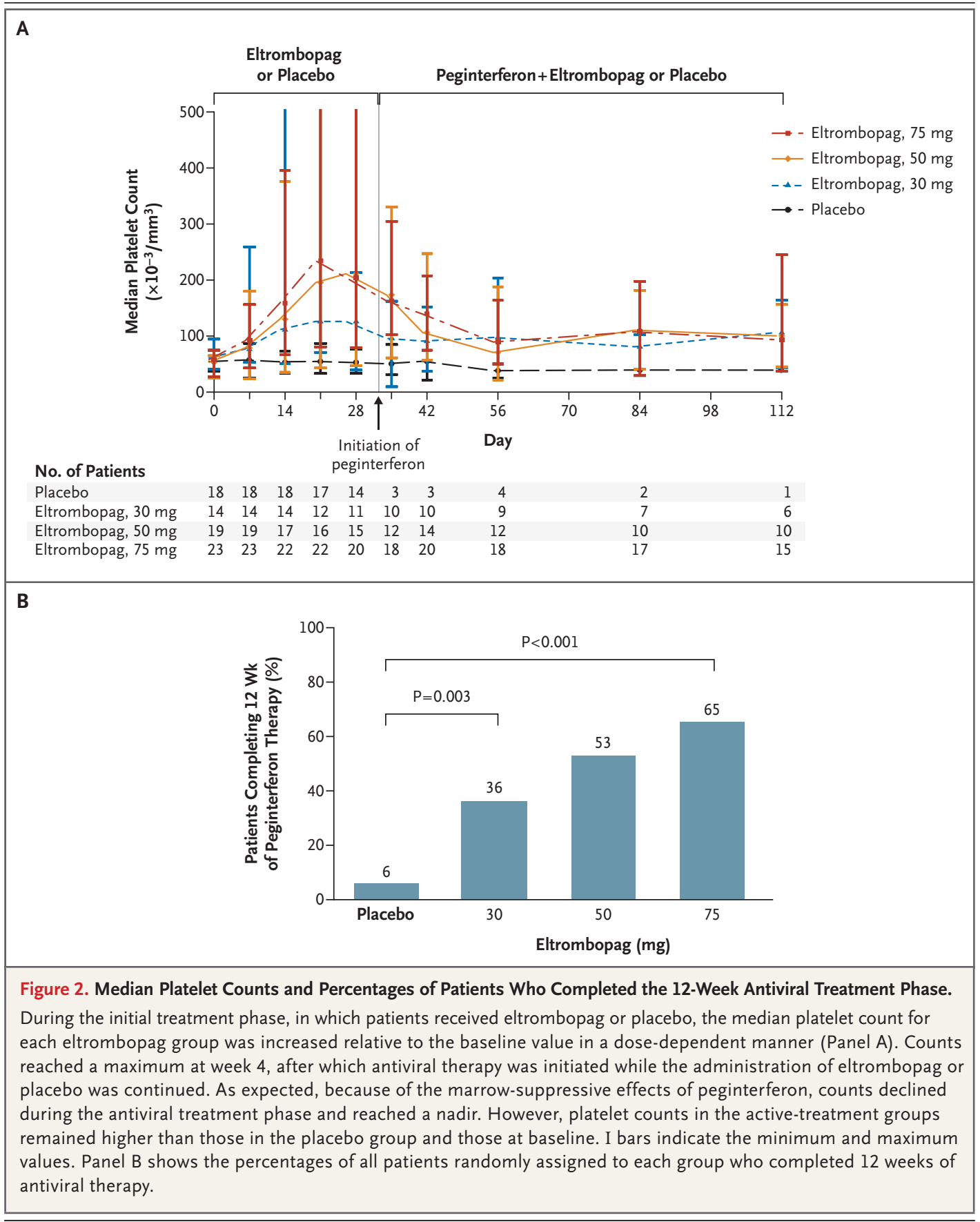

one patient receiving $50 \mathrm{mg}$ of eltrombopag were resolving at the end of the study. The thrombocytopenia occurred after eltrombopag therapy had been discontinued and peginterferon administration had begun; the platelet count fell below the patient's baseline count, and the event was considered by the investigator to be related to the study drug. One patient in the placebo group had two reported serious adverse events, abdominal pain and renal failure, and subsequently died. Adverse events led to the withdrawal of three patients receiving $30 \mathrm{mg}$ of eltrombopag (owing to upper abdominal pain and ascites), one patient receiving $50 \mathrm{mg}$ of eltrombopag (owing to neutropenia), and one patient receiving $75 \mathrm{mg}$ of eltrombopag (owing to retinal exudates). 


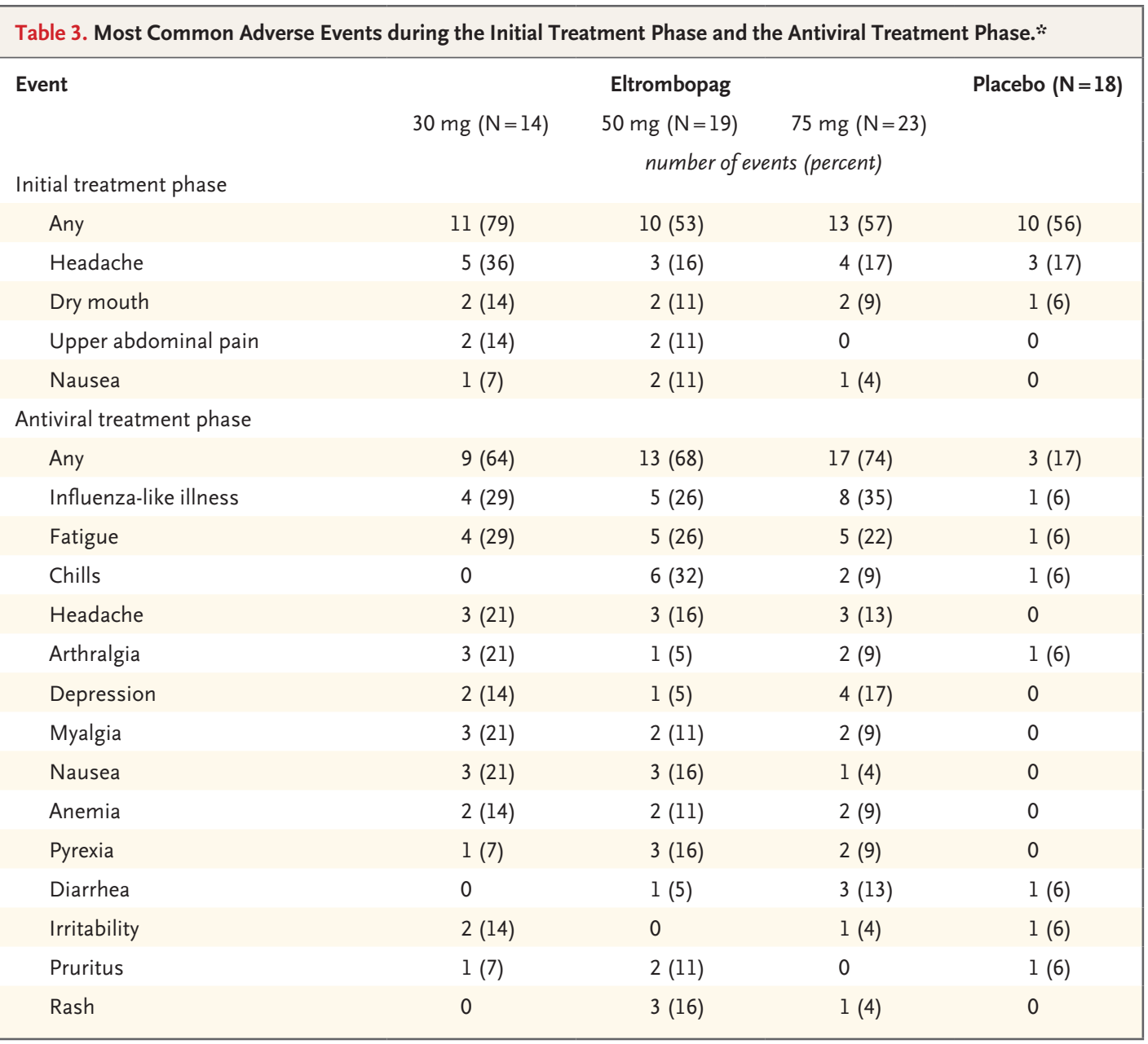

* The adverse events listed are those that occurred in more than $3 \%$ of patients in any group.

\section{DISCUSSION}

Thrombocytopenia in patients with cirrhosis due to HCV can prevent or limit antiviral treatment, but there is little information concerning the eligibility for treatment of patients with platelet counts of less than 50,000 per cubic millimeter. In our study, 30 of 45 patients who had had a response to eltrombopag, with a rise in the platelet count to 70,000 or more per cubic millimeter (or $\geq 100,000$ per cubic millimeter) during the initial treatment phase, completed the first 12 weeks of antiviral treatment with peginterferon, during which time the use of eltrombopag was continued; specifically, $65 \%$ of those receiving $75 \mathrm{mg}$ of eltrombopag and $53 \%$ of those receiving $50 \mathrm{mg}$ of eltrombopag completed the first 12 weeks of the treatment.
The most common side effects of eltrombopag during the initial treatment phase were headache, dry mouth, abdominal pain, and nausea; these effects were of insufficient severity to require discontinuation of the drug. In this small and therefore underpowered study, we did not find evidence of a dose-response relation with respect to the occurrence of adverse events in the antiviral treatment phase, during which the reported side effects were consistent with those associated with interferon-based therapy.

During the initial treatment phase, significant increases in platelet counts were observed in each of the three eltrombopag groups as compared with the placebo group. The primary end point (a platelet count $\geq 100,000$ per cubic millimeter at week 4) was met in 75 to $95 \%$ of patients in the eltrombopag groups, in a dose-dependent man- 
ner. During the subsequent antiviral phase, platelet counts decreased, perhaps owing to the antiplatelet effect of peginterferon; nevertheless, platelet counts remained consistently above baseline levels. These results require confirmation in phase 3 trials involving standard-duration courses of peginterferon and ribavirin.

Supported by GlaxoSmithKline.

Drs. McHutchison, Dusheiko, Shiffman, Rodriguez-Torres, Sigal, Bourliere, Berg, Gordon, and Afdhal report receiving research and grant support from GlaxoSmithKline; Drs. McHutchison, Dusheiko, Shiffman, Rodriguez-Torres, Gordon, and Afdhal, research and grant support from Roche and Schering-Plough; Drs. McHutchison, Dusheiko, Rodriguez-Torres, Sigal, Gordon, and Afdhal, consulting or advisory fees from GlaxoSmithKline; Drs. Dusheiko, Shiffman, Rodriguez-Torres, and Bourliere, consulting fees from Roche; Drs. McHutchison, Dusheiko, and Afdhal, consulting fees from Schering-Plough; Drs. McHutchi- son and Gordon, lecture fees from GlaxoSmithKline, ScheringPlough, and Roche; Drs. Dusheiko and Bourliere, lecture fees from Schering-Plough and Roche; Drs. Shiffman and RodriguezTorres, lecture fees from Roche; and Dr. Afdhal, lecture fees from GlaxoSmithKline and Schering-Plough. Duke University has a funded academic alliance with GlaxoSmithKline that has also supported clinical and translational research by Dr. McHutchison and other Duke investigators. Dr. Theodore, Ms. Campbell, and Drs. Blackman and Jenkins report being employees of GlaxoSmithKline and holding stock therein. No other potential conflict of interest relevant to this article was reported.

We thank the study coordinators, nurses, and patients involved in the study; Steven Mangum, Dr. Valerie Kitchen, and Dawn Midwinter for their input and insights into the design of the study; Drs. Scott White, Helen Steel, Michael Arning, and Yizhe Wang from GlaxoSmithKline and Dr. James Bussel for their instructive comments and assistance during the preparation of an earlier version of the manuscript; and the staff of AOI Communications and Larry Rosenberg, Ph.D., for their editorial assistance with an earlier version of the manuscript.

\section{APPENDIX}

In addition to the authors, the participating investigators in the TPL102357 Study Group were as follows: Centre Hospitalier Universitaire de Nancy, Hôpital pour Adultes de Brabois, Vandoeuvre-lès-Nancy, France — J.P. Bronowicki; Hôpital du Haut Lévêque, Pessac, France — V. DeLédinghen; Hôpital Edouard Herriot, Lyon, France — J. Dumortier; Universitaetsklinikum Heidelberg, Innere Medizinische IV, Heidelberg, Germany — J. Encke; Papageorgiou General Peripheral Hospital, Thessaloniki, Greece - G. Germanidis; Alamo Medical Research, San Antonio, TX - E. Lawitz; Hôpital Beaujon, Clichy, France - P. Marcellin; Gartnavel General Hospital, Glasgow, United Kingdom - P. Mills; Hôpital Saint Antoine, Paris — R. Poupon; Metropolitan Research, Fairfax, VA - V. Rustgi; Klinikum der J.W. Goethe Universitaet-Medizinische Klinik III, Frankfurt, Germany — G. Teuber; Hôpital L'Archet, Nice, France - A. Tran; Centre Hospitalier Universitaire de Grenoble, Hôpital Nord Michallon, Grenoble, France — J.P. Zarski.

\section{REFERENCES}

1. Giannini EG. Thrombocytopenia in chronic liver disease and pharmacologic treatment options. Aliment Pharmacol Ther 2006;23:1055-65.

2. Peck-Radosavljevic M. Thrombocytopenia in liver disease. Can J Gastroenterol 2000;14:Suppl D:60D-66D.

3. Bashour FN, Teran JC, Mullen KD. Prevalence of peripheral blood cytopenias (hypersplenism) in patients with nonalcoholic chronic liver disease. Am J Gastroenterol 2000;95:2936-9.

4. McCormick PA, Murphy KM. Splenomegaly, hypersplenism and coagulation abnormalities in liver disease. Baillieres Best Pract Res Clin Gastroenterol 2000; 14:1009-31.

5. Adinolfi LE, Giordano MG, Andreana A, et al. Hepatic fibrosis plays a central role in the pathogenesis of thrombocytopenia in patients with chronic viral hepatitis. Br J Haematol 2001;113:590-5.

6. Rios R, Sangro B, Herrero I, Quiroga J, Prieto J. The role of thrombopoietin in the thrombocytopenia of patients with liver cirrhosis. Am J Gastroenterol 2005; 100:1311-6.

7. Bordin G, Ballaré $M$, Zigrossi $P$, et al. A laboratory and thrombokinetic study of HCV-associated thrombocytopenia: a direct role of $\mathrm{HCV}$ in bone marrow exhaus- tion? Clin Exp Rheumatol 1995;13:Suppl 13:S39-S43.

8. Ballard HS. Hematological complications of alcoholism. Alcohol Clin Exp Res 1989;13:706-20.

9. McHutchison JG, Manns M, Patel K, et al. Adherence to combination therapy enhances sustained response in genotype1-infected patients with chronic hepatitis C. Gastroenterology 2002;123:1061-9.

10. Shiffman ML, Ghany MG, Morgan TR, et al. Impact of reducing peginterferon alfa-2a and ribavirin dose during retreatment in patients with chronic hepatitis C. Gastroenterology 2007;132:103-12.

11. Luengo JI, Duffy KJ, Shaw AN, et al. Discovery of SB-497115, a small-molecule thrombopoietin (TPO) receptor agonist for the treatment of thrombocytopenia. Blood 2004;104:2910. abstract.

12. Jenkins JM, Williams D, Deng Y, et al. Phase I clinical study of eltrombopag, an oral, nonpeptide thrombopoietin receptor agonist. Blood 2007;109:4739-41.

13. Sellers T, Hart T, Semanik M, Murthyl K. Pharmacology and safety of SB-497115GR, an orally active small molecular weight TPO receptor agonist, in chimpanzees, rats and dogs. Blood 2004;104:2063. abstract. 14. Erickson-Miller CL, Luengo JI, Nicholl $\mathrm{R}$, et al. In vitro and in vivo biology of a small molecular weight TPO receptor agonist, SB-497115. Poster presented at the 96th American Association for Cancer Research Annual Meeting, Anaheim, CA, April 16-20, 2005. abstract.

15. Erhardt J, Erickson-Miller CL, Tapley P. SB 497115-GR, a low molecular weight TPOR agonist, does not induce platelet activation or enhance agonist-induced platelet aggregation in vitro. Blood 2004;104: 3888. abstract.

16. Provan D, Saleh M, Goodison S, et al. The safety profile of eltrombopag, a novel, oral platelet growth factor, in thrombocytopenic patients and healthy subjects. J Clin Oncol 2006;24:Suppl:18S. abstract. 17. Bussel JB, Cheng G, Saleh MN, et al. Eltrombopag for the treatment of chronic idiopathic thrombocytopenic purpura. N Engl J Med 2007;357:2237-47.

18. O'Brien PC, Fleming TR. A multiple testing procedure for clinical trials. Biometrics 1979;35:549-56.

19. Gutfreund KS, Bain VG. Chronic viral hepatitis C: management update. CMAJ 2000;162:827-33.

20. Manns MP, Wedemeyer H, Cornberg M. Treating viral hepatitis C: efficacy, side effects, and complications. Gut 2006;55: 1350-9.

Copyright (c) 2007 Massachusetts Medical Society. 